\title{
THE DETERMINATION OF SILICATE IN SEA WATER
}

\author{
By F. A. J. Armstrong \\ Experimental Officer at the Plymouth Laboratory
}

(Text-figs. I-3)

Silicon in sea water may be present in suspension, in particles of clay or sand, as a constituent of diatoms, etc., or in solution. Some silicon in solution occurs in the form of silicate. This is usually estimated by the colorimetric method of Diénert \& Wandenbulcke (I923), which makes use of the yellow colour of the silicomolybdic acid which is formed when ammonium molybdate and sulphuric acid are added to the water (Atkins, 1923). The colour may be compared with that of standard solutions of picric acid (Diénert \& Wandenbulcke, I923) or potassium chromate (Swank \& Mellon, I934). The method is simple but the colour in sea water is often faint and is not easy to match visually, nor is its intensity strictly proportional to the concentration of silicate. Less colour is produced in sea water than in standard solutions made with distilled water and this 'salt error' must be allowed for (Brujewicz \& Blinov, I933; Wattenberg, I937; Robinson \& Spoor, I936).

The work described below was done in an attempt to apply to sea water the more sensitive method in which silicomolybdic acid is formed and then reduced to molybdenum blue, a method which is now often used for determining trace amounts of silicon in other materials. It was found that this could be done, and an analytical method devised which would allow the determination of silicate in a range of concentrations from O. I to $50 \mu \mathrm{g}$. atoms $\mathrm{Si} / 1$.

The method adopted is based upon the results of an investigation of the properties of silicomolybdic acid by Strickland (I950), which are summarized below.

Strickland found that when silicic acid reacts with molybdate, two forms of silicomolybdic acid may be formed, depending on the degree of acidification of the molybdate. When the normal molybdate ion is acidified with $\mathrm{I} \cdot 45$ to $\mathrm{I} \cdot 50$ equivalents of acid per g. ion of $\mathrm{MoO}_{4}{ }^{--}$, then the silicomolybdic acid described in the literature is the main product of the reaction. He terms this $\alpha$-silicomolybdic acid to distinguish it from the other form, which he calls $\beta$-silicomolybdic acid, produced when silicic acid reacts with molybdate acidified with more than about 2 equivalents of acid per $\mathrm{g}$. ion of $\mathrm{MoO}_{4}^{--}$. He states, further, that the presence of much electrolyte in solution decreases the ratio of $\beta$-to $\alpha$-compounds formed at a given acidity. Moreover, over a period of several hours the $\beta$-form changes spontaneously and irreversibly into the $\alpha$-form. The $\beta$-compound has apparently the same empirical formula as the $\alpha$-compound and has a similar but more intense yellow colour, the extinction for a given quantity of combined silica being over twice as great. 
These findings, which I have confirmed, are consistent with reports in the literature of non-reproducibility and fading of the colour.

Strickland also investigated the reduction of these compounds by stannous chloride. In the presence of excess molybdate, both form blue compounds, but of different appearance and absorption spectra. That from the $\alpha$-acid, which is greenish blue, has over $\mathrm{I} \frac{1}{2}$ times the molecular extinction coefficient of that from the $\beta$-acid, which is royal blue.

For analytical use Strickland recommends preparation of the $\beta$-compound as more reproducible, and for this purpose it is necessary to acidify the molybdate with between 3 and 5 equivalents of acid. A concentration of molybdate, such that $[\mathrm{Mo}]=0.5 \mathrm{M}$ remains after the silica has combined, is suitable for all concentrations of silicate, but the ionic strength of other ions must not exceed $0.5 \mathrm{M}$. Formation of the complex is complete in 5-10 min., and absorption measurement or subsequent reduction should not be delayed for longer than a further $15 \mathrm{~min}$.

It is also known that for reduction, the stannous chloride may not be added immediately to these weakly acid solutions, or the excess molybdate will be reduced to a blue compound. If, however, the solution is first made approximately I $\mathrm{N}$ with $\mathrm{HCl}$, or I. $5 \mathrm{~N}$ with $\mathrm{H}_{2} \mathrm{SO}_{4}$, the excess molybdate is converted rapidly (in about half a minute) into a form which will not reduce to a blue. Upon addition of stannous chloride only the silicomolybdic acid is reduced to molybdenum blue, but some of the excess molybdate is reduced to a substance of brownish yellow colour, probably a quinquevalent molybdenum compound. The amount of this increases with increasing molybdate, chloride, and stannous chloride concentrations. This compound has a measurable light absorption with the red light-filters used for measurement of absorption of molybdenum blue, and contributes to the 'reagent blank' of the method.

\section{EXPERIMENTAL}

Extinctions of coloured solutions were measured with the absorptiometer already described (Harvey, I948). With it extinctions up to 0.5 can be measured to the nearest $0.00 \mathrm{I}$, and it will accommodate cuvettes of up to $25 \mathrm{~cm}$. length. The distilled water used was prepared in a still having a silver condenser and was assumed to be silicon free.

As a basis for comparison the Diénert-Wandenbulcke method, as adapted by Atkins, was used, and series of solutions with known additions of silicon as silicate were prepared from distilled and sea water. To Ioo $\mathrm{ml}$. portions of these were added $2 \mathrm{ml}$. of $10 \%$ ammonium molybdate and 4 drops of $50 \%$ $\mathrm{v} / \mathrm{v}$ sulphuric acid. The extinctions of the resulting yellow solutions were measured in a $20 \mathrm{~cm}$. cuvette with Chance OB I (blue) and then with Ilford 6oI (violet) filters in the absorptiometer. The results are shown in Fig. IA. It will be seen that the relationship between extinction and silicon concentration is not linear, though the curvature is less with the 6oI filter (which transmits light of shorter wave-length) and the sensitivity is greater. The decrease in sensitivity in sea water is also to be seen.

A test of the molybdenum-blue method was made as follows. In each of a series of $100 \mathrm{ml}$. flasks $5 \mathrm{ml}$. of $5 \%$ ammonium molybdate and $3 \mathrm{ml}$. I Nhydrochloric acid was placed, and $25 \mathrm{ml}$. of distilled or sea water containing 

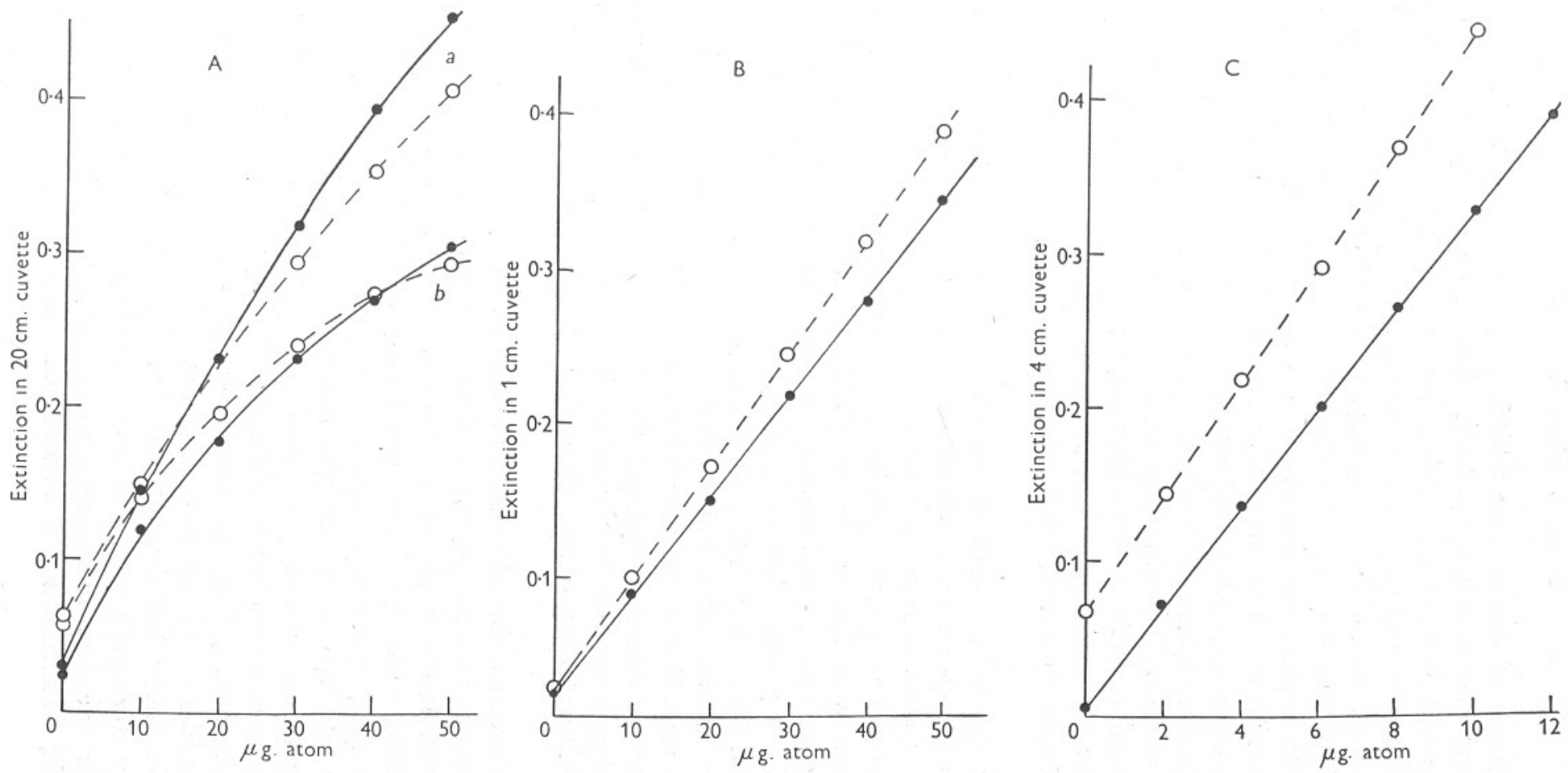

Fig. I. The relation between extinction and silicate concentration '(A) with the Diénert-Wandenbulcke method; (B) with the molybdenum-blue method; (c) with the molybdenum-blue method, quantity of molybdate reduced. Silicon added (horizontal scale) in $\mu \mathrm{g}$. atom Si/l. $a$, Ilford 60I filter (violet); $b$, Chance OB I filter (blue). Continuous line, distilled water; broken line, sea water. 
known additions of silicon were added. After Io min. $5 \mathrm{ml}$. of $35 \% \mathrm{v} / \mathrm{v}$ sulphuric acid were added, the solution allowed to stand $5 \mathrm{~min}$., and I $\mathrm{ml}$. O. I N-stannous chloride added. After a further Io min. the extinctions of the solutions were measured in a I cm. cuvette, using Chance OR I (red) filters. These were used because they are already in use for phosphate determinations; Ilford 608 Spectrum Red filters are equally suitable. The results are shown in Fig. I B, which displays the linearity of the relationship between extinction and silicon concentration. The sensitivity in sea water is greater, indicating that some $\alpha$-silicomolybdate has been formed.

The molybdenum-blue method is thus about $\mathrm{I} 6$ times more sensitive than the older procedure. The advantage cannot, however, be exploited by using a longer cuvette to increase extinction values unless the reagent blank (which would increase proportionally) can be decreased. With distilled water with no added silicon the extinction is 0.015 , which is equivalent to about $2 \mu \mathrm{g}$. atoms $\mathrm{Si} / 1$.

As a first step toward reducing the blank, a method of eliminating interference from phosphate and arsenate was tried. (There are usually a few parts per million of phosphate in the reagents which contribute to the blank.) In sea water the concentrations of phosphate and arsenate are normally negligible in comparison with that of silicate. An experiment showed that with the procedure given above, equal extinctions were produced by IOI $\mu \mathrm{g}$. of Si as silicate, $85 \mu \mathrm{g}$. P as phosphate, and $235 \mu \mathrm{g}$. As as arsenate. It has been shown (Denis \& von Meysenbug, I922; Bordeionu, 1927; Riehm, 1932) that oxalic (or citric or tartaric) acids will suppress interference from phosphate and arsenate. A trial showed that the addition of $2 \mathrm{ml}$. of $10 \%$ oxalic acid to the solution after acidification with sulphuric acid completely suppressed the formation of molybdenum blue from added phosphate and arsenate, leaving the extinction caused by silicate unchanged. The blank extinction decreased to 0.012 .

A further decrease should result if the amounts of molybdate and stannous chloride could be reduced, and was realized by the following procedure.

In a $100 \mathrm{ml}$. flask were placed $50 \mathrm{ml}$. of the sample, and $2 \mathrm{ml}$. of a reagent made by mixing 5 vol. of $5 \%$ ammonium molybdate and 3 vol. of I N-hydrochloric acid. After standing Io min., $5 \mathrm{ml}$. of $50 \%$ sulphuric acid and $2 \mathrm{ml}$. of 10\% oxalic acid were added and the extinction measured in the absorptiometer, using a $4 \mathrm{~cm}$. cuvette. (This gave a measure of the natural turbidity of the solution, to be subtracted from the final reading to give a true measure of the colour produced.) Ten min. after acidification I ml. of $0.05 \mathrm{~N}$-stannous chloride was added, and the extinction measured after a further $15 \mathrm{~min}$.

Results for known additions of silicon to distilled water and to a sample of sea water comparatively low in silicate are shown in Fig. IC. The plots remain linear; the slope, indicating sensitivity, being greater for the sea water. The blank for distilled water, of 0.007 , represents a concentration of $0.19 \mu \mathrm{g}$. 
atom $\mathrm{Si} / 1$. The reagent blank in sea water, which is greater than in distilled water because the high concentration of chloride causes increased formation of the yellowish quinquevalent compound, cannot be found directly unless silicatefree sea water can be obtained. The silicon content of the sample of sea water is not given by this experiment. The way in which the blank is found is described below.

As was mentioned above, the blank has two components, molybdenum blue due to silicon in the reagents, and the quinquevalent molybdenum colour due to reduction of excess molybdate. Provided that it is small the correction for silicon in the reagents is the same in distilled water and in sea water. The quinquevalent molybdenum colour is, however, greater in water containing chloride. It may be found directly by making the solution strongly acid before adding the molybdate; in $\mathrm{I} \cdot 5 \mathrm{~N}$-acid solution silicate will not combine with molybdate, and on adding stannous chloride the only colour produced is that due to reduction of excess molybdate.

Three measurements will then allow the blank correction for sea water to be calculated: (i) the extinction with silicon-free distilled water carried through the normal procedure; (ii) the extinction with distilled water when the $5 \mathrm{ml}$. $50 \% \mathrm{v} / \mathrm{v}$ sulphuric acid is added before the molybdate reagent, addition of oxalic acid and stannous chloride following as usual; (iii) the extinction with sea water carried through the procedure of (ii) above.

The difference between measurements (i) and (ii) is the extinction due to silicate in the reagents, and must be added to measurement (iii) to obtain the total blank correction. This is to be subtracted from extinction measurements made upon sea water.

The method at this stage of development was put into use for silicate determinations on samples of sea water, and was found to work fairly well, although the reproducibility of calibration with known additions of silicate was not entirely satisfactory. More disturbing was the occurrence of occasional high figures as if contamination had taken place. This effect was traced to attack of the resistance glass of the flasks by the sea water before addition of the molybdate reagent, and was surprisingly large. Several micrograms of silicon were dissolved in $30 \mathrm{~min}$. It was found that placing the molybdate reagent in the flask first and then adding the sea water prevented this, presumably because the solution was now acid instead of faintly alkaline.

Variations in calibration figures were thought to be due to variation in the proportion of $\alpha$-silicomolybdate formed, and so should be reduced if this could be decreased. The difference in the slopes of the lines in Fig. I B indicates that about $30 \%$ of the silicomolybdate formed in sea water is in the $\alpha$-form. An increase of the acidity of the reagent to the maximum recommended by Strickland was therefore tried, the reagent being made by mixing 2 vol. of $5 \%$ ammonium molybdate and 3 vol. of I N-hydrochloric acid. When $3 \mathrm{ml}$. of this reagent was used (in place of the $2 \mathrm{ml}$. previously employed) the 
sensitivity in sea water was nearer to that in distilled water, and corresponded to about $12 \% \alpha$-silicomolybdate formation. In subsequent routine use the calibration factors with this reagent were satisfactorily constant.

The data obtained so far were got in a laboratory at fairly constant temperature, and care had been taken to adhere to the stated timing. The usefulness of the method would be increased if it were known what latitude could be allowed, and a few experiments were done to find this out.

Fig. 2A shows the effect of temperature upon the depth of colour produced by a given quantity of silicate, the temperature being that at which the sea water and molybdate were allowed to react, the solutions being brought to $20^{\circ} \mathrm{C}$. for the rest of the procedure. It is seen that the change in extinction with temperature is about 2 parts $/ 1000 /{ }^{\circ} \mathrm{C}$.

Fig. 2 B shows the effect of altering the time of interaction (at $18^{\circ} \mathrm{C}$.) of the sea water and molybdate, i.e. the time between addition of the sample and acidification with sulphuric acid. The maximum extinction is produced after IO-I5 min.

Fig. 3 shows the development and subsequent fading of colour at temperatures of 13 and $22^{\circ} \mathrm{C}$. The upper curves are of extinctions with (different) samples of sea water and represent the colour due to the combined effect of the molybdenum blue and the quinquevalent molybdenum blank, while the lower line is that of the latter alone, which was the same at both temperatures. The colour reached a maximum after $60 \mathrm{~min}$. at $13^{\circ} \mathrm{C}$. and after $30 \mathrm{~min}$. at $22^{\circ} \mathrm{C}$. and was within I \% of this maximum between about 40 and 70 , and I6 and $32 \mathrm{~min}$. respectively. In distilled water the colour attains its maximum within $3-5 \mathrm{~min}$. and is constant for about $3 \mathrm{hr}$. at $20^{\circ} \mathrm{C}$.

These times are longer than had been allowed in the earlier experiments, and have been used as a guide in subsequent work.

\section{Solutions required}

\section{RECOMMENDED PROCEDURE}

(I) Ammonium molybdate, $5 \% \mathrm{w} / \mathrm{v}$.

(2) Hydrochloric acid, I N.

(3) Sulphuric acid, $50 \% \mathrm{v} / \mathrm{v}$.

(4) Oxalic acid, $10 \% \mathrm{w} / \mathrm{v}$.

(5) Stannous chloride, $0.05 \mathrm{~N}$.

(6) Standard silicate solution.

The ammonium molybdate and hydrochloric acid solutions should be prepared from A.R. grade materials and silicon-free distilled water, and kept in polyethylene, ceresin, or heavily waxed bottles. The mixed reagent for use, consisting of 2 vol. molybdate and 3 vol. acid, should be freshly prepared, as it sometimes throws down a precipitate on standing for I or 2 days.

The stannous chloride is conveniently made just before it is required, by dilution from a stock solution of, say, $40 \mathrm{~g}$. $\mathrm{SnCl}_{2} \cdot 2 \mathrm{H}_{2} \mathrm{O}$ in $100 \mathrm{ml} .50 \% \mathrm{v} / \mathrm{v} \mathrm{HCl}$. 


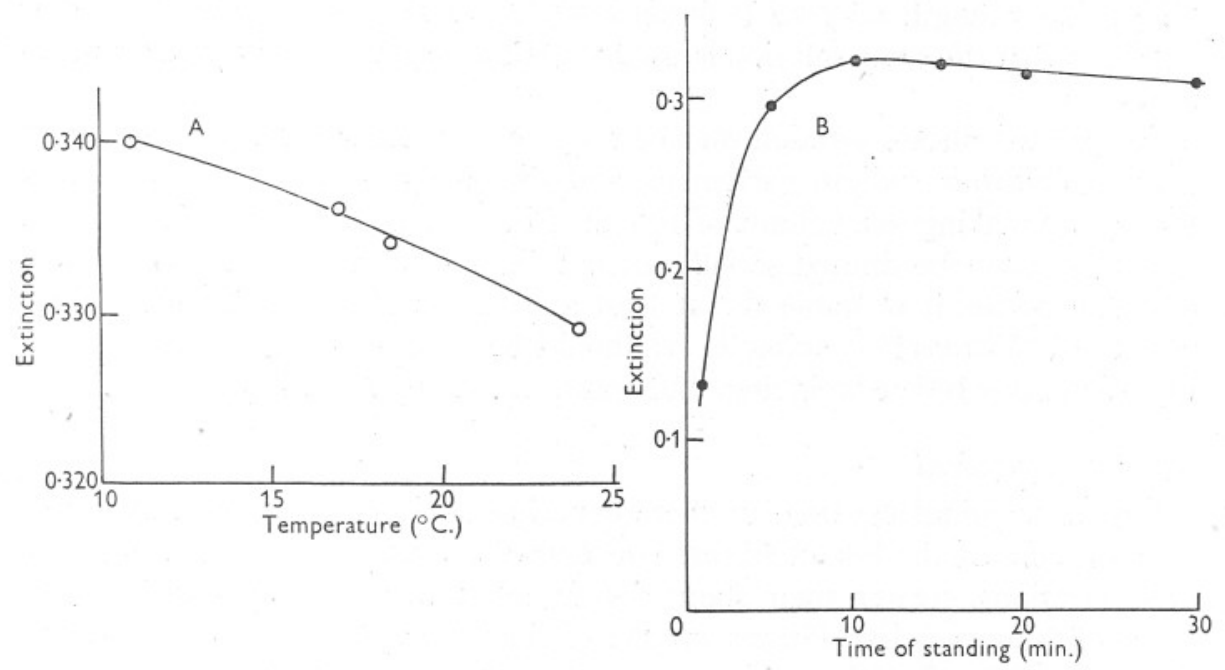

Fig. 2. A, The effect of temperature upon the amount of molybdenum blue formed, in seawater. Extinction in $4 \mathrm{~cm}$. cuvette given by about Io $\mu \mathrm{g}$. atoms Si/1. B, The effect of time upon the interaction of silicate and acid molybdate. Extinction in $4 \mathrm{~cm}$. cuvette.

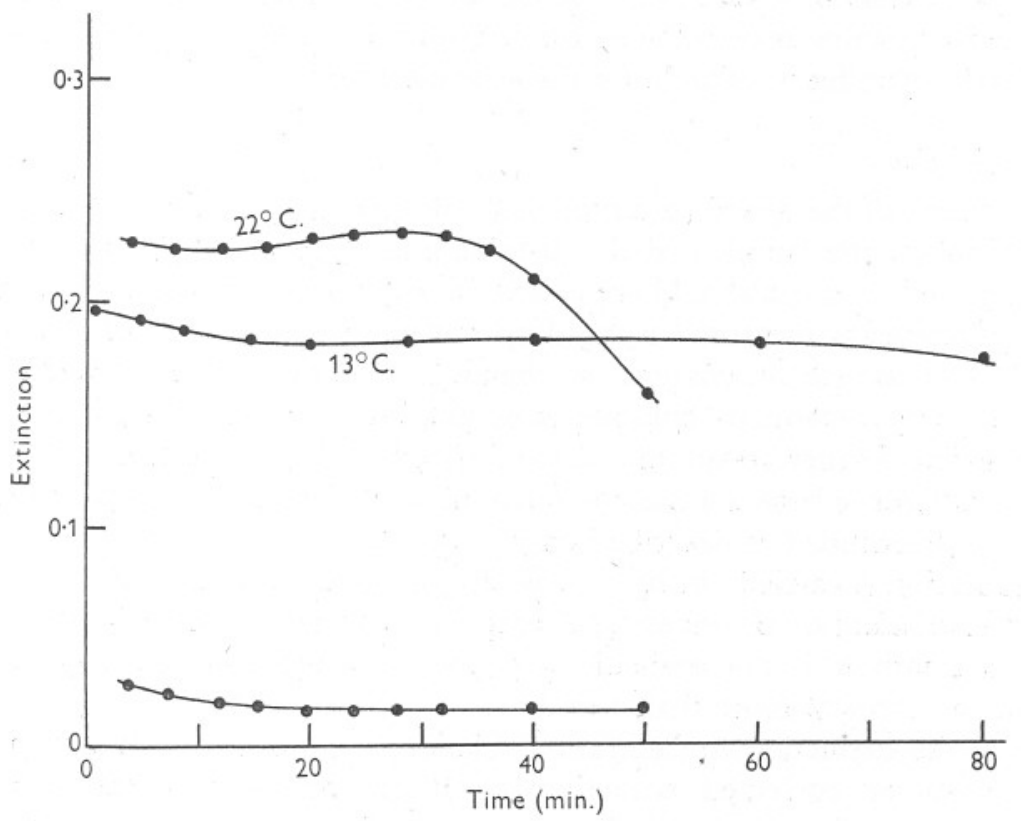

Fig. 3. Changes in the extinction of sea-water solutions with time. The lower line shows the quinquevalent molybdenum blank, which was the same at the two temperatures used. 
The exact strength may be between 0.04 and $0.06 \mathrm{~N}$, and is not important provided that the same solution is used for both the blanks and the determinations.

A standard silicate solution may be prepared by fusing $0.120 \mathrm{I}$ g. silica with $0.6 \mathrm{~g}$. anhydrous sodium carbonate, and dissolving the melt when cold in water, and making to a volume of $100 \mathrm{ml}$. This solution contains $20 \mu \mathrm{g}$. atoms $\mathrm{Si} / \mathrm{ml}$, and can be diluted serially for use. If kept in a well-stoppered polyethylene bottle, it is stable for at least a year. As a source of silica, finely powdered 'Vitreosil' is suitable. It should be heated to redness and cooled in a desiccator before weighing, and contains over $99 \cdot 8 \% \mathrm{SiO}_{2}$.

\section{Apparatus required}

The absorptiometer used in these experiments is very convenient, but is only essential if the lowest silicate concentrations have to be measured. For concentrations greater than about $0.5 \mu \mathrm{g}$. atom Si/1. the 'Spekker' instrument of Messrs Adam Hilger, or one of the other photoelectric absorptiometers capable of holding a $4 \mathrm{~cm}$. cuvette, would serve. The method can of course be used with a visual absorptiometer or with Nessler cylinders with a small loss of precision and speed. With the latter a comparator system would be necessary because of the mixture of blue and yellow colours.

Polyethylene bottles are desirable for samples and some reagents. Ordinary (grade B) pipettes may be used for measuring out the reagents. A $50 \mathrm{ml}$. graduated cylinder is suitable for the sea-water sample.

\section{Determination}

Three $\mathrm{ml}$. of the mixed acid molybdate reagent are placed in a $100 \mathrm{ml}$. flask and $50 \mathrm{ml}$. of the sample added. After Io min. $5 \mathrm{ml}$. of $50 \%$ sulphuric acid and $2 \mathrm{ml}$. of $10 \%$ oxalic acid are added. The extinction of the solution in the absorptiometer is measured using deep red filters. The length of the cuvette should suit the silicon content (see below). Five minutes after acidification I ml. of $0.05 \mathrm{~N}$-stannous chloride is added, and the extinction is measured again after a further $20-40 \mathrm{~min}$. depending upon the temperature.

The difference between these two readings must be corrected for the blank which is determined as described on p. 153 .

Calibration is carried out by measuring the increase in extinction produced by a known addition of silicate to a sample of sea water of low silicon content. If such a sample is not available, $3.5 \% \mathrm{w} / \mathrm{v}$ sodium chloride may be used without an error of more than I or $2 \%$.

Since the extinction/concentration relationship is linear a factor may be used to convert corrected extinctions to silicon content. For example, with a $4 \mathrm{~cm}$. cuvette, an extinction of $\mathrm{r} \cdot 00$ corresponds to about $27 \mu \mathrm{g}$. atoms $\mathrm{Si} / \mathrm{l}$. Using an absorptiometer which measures extinctions up to 0.5 , the cuvette lengths suitable for different ranges of silicon concentrations are as follows: 


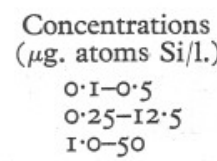

Cuvette length (cm.)

IO

I

A worked example will illustrate the method of calculation. With a $4 \mathrm{~cm}$. cuvette, the following extinctions were obtained.

\section{Blank}

Distilled water, normal order of addition of reagents;

Before adding stannous chloride 0.000

After adding stannous chloride $\quad 0.006$

Distilled water, $\mathrm{H}_{2} \mathrm{SO}_{4}$ added before molybdate:

Before adding stannous chloride 0.000

After adding stannous chloride $\quad 0.004$

The extinction due to silicon in the reagents is therefore $0.006-0.004=0.002$.

Sea water, $\mathrm{H}_{2} \mathrm{SO}_{4}$ added before molybdate:

Before adding stannous chloride 0.007

After adding stannous chloride 0.013

The quinquevalent molybdenum blank for sea water is therefore $0.013-0.007=0.006$, and if to this is added 0.002 for the silicon in the reagents, the total 0.008 , is the blank to be subtracted from measurements on sea water.

\section{Calibration}

Sea water, normal addition of reagents:

\section{Before adding stannous chloride 0.005}

After adding stannous chloride 0.048

The same sea water, to which 10॰ $\mu \mathrm{g}$. atoms $\mathrm{Si} / 1$. have been added:

$\begin{array}{ll}\text { Before adding stannous chloride } & 0.005 \\ \text { After adding stannous chloride } & 0.420\end{array}$

The extinction due to the addition of $10.0 \mu \mathrm{g}$. atoms $\mathrm{Si} / 1$. is thus $(0.420-0.005)-$ $(0.048-0.005)=0.372$, so that an extinction of $\mathrm{I} .00$ corresponds to $10.0 \times \frac{\mathrm{I} \cdot 00}{0.372}$ or $26 \cdot 9 \mu \mathrm{g}$. atoms $\mathrm{Si} / 1$.

\section{Sample}

Sea-water sample, normal order of addition of reagents:

$$
\begin{array}{ll}
\text { Before adding stannous chloride } & 0.006 \\
\text { After adding stannous chloride } & 0.28 \mathrm{I}
\end{array}
$$

The extinction for the sea water, corrected for turbidity, is thus $0.28 \mathrm{I}-0.006$ or 0.275 , and from this figure 0.008 must be subtracted for the total blank, leaving 0.267 .

The silicon content of the sample is then $0.267 \times 26 \cdot 9$ or $7 \cdot 18 \mu \mathrm{g}$. atoms $\mathrm{Si} / \mathrm{l}$.

\section{Reproducibility}

Replicate analyses usually agree within $\pm 3 \%$. Five analyses of a sample of sea water gave the following results: II.53, II.55, II.6I, II.6I, II.63 $\mu \mathrm{g}$. atoms $\mathrm{Si} / 1$. 


\section{Time needed}

Analysis of ten samples, with blanks and calibration, may be done in about $2 \mathrm{hr}$. Calibration is needed only occasionally.

\section{Storage of samples}

Samples should be collected in polyethylene or heavily waxed bottles, and kept in the dark to prevent multiplication of diatoms, which may consume silicate. They should not be kept long before analysis, since suspended siliceous matter may dissolve forming soluble silicate. A series of samples gave the following figures before and after storage for 3 months:

\begin{tabular}{|c|c|c|c|c|c|c|c|c|c|c|c|c|}
\hline Date of & & & & & & icate & $\mu \mathrm{g}$. atc & $\mathrm{ms} \mathrm{Si}$ & & & & \\
\hline $\begin{array}{l}\text { 28. viii. } 50 \\
\text { 17. xi. } 50\end{array}$ & - & $\begin{array}{l}19.0 \\
15.6\end{array}$ & $\begin{array}{l}2.45 \\
2.47\end{array}$ & $\begin{array}{l}0.94 \\
1.06\end{array}$ & $\begin{array}{l}I \cdot I 2 \\
I \cdot 27\end{array}$ & $\begin{array}{l}0.79 \\
1.01\end{array}$ & $\begin{array}{l}0.56 \\
0.80\end{array}$ & $\begin{array}{l}0.47 \\
0.83\end{array}$ & $\begin{array}{l}0.47 \\
0.81\end{array}$ & $\begin{array}{l}\mathrm{I} \cdot 9 \mathrm{I} \\
2 . \mathrm{I}\end{array}$ & $\begin{array}{l}2 \cdot 12 \\
2 \cdot 30\end{array}$ & $\begin{array}{l}2.34 \\
2.66\end{array}$ \\
\hline Increase (\%) & & -18 & I & I3 & I3 & 28 & 43 & 77 & 72 & I5 & 9 & I4 \\
\hline
\end{tabular}

Dr W. R. G. Atkins (private communication) has found a similar increase in the silicate content of samples of sea water stored in polyethylene bottles for about the same time.

\section{SOME RESUlTS}

Samples from the surface at the Laboratory Stations $\mathrm{L} 2$ to $\mathrm{L} 6$ and from various depths at International Hydrographic Station E I have been analysed by this method since March I950, with the results given in Table I. They show high values at the surface near Plymouth, due to land drainage, decreasing with distance off-shore, although the effect is noticeable I2 miles out. They show,

Table I. Silicate OfF-Shore from Plymouth ( $\mu$ g. atoms Si/L.)

\begin{tabular}{|c|c|c|c|c|c|c|c|c|c|c|c|}
\hline Station & $\begin{array}{l}\text { Miles from } \\
\text { laboratory }\end{array}$ & $\begin{array}{l}\text { Depth } \\
\text { (m.) }\end{array}$ & 24 Mar. & 3 May & 23 May & I2 June & I9 July & 23 Aug. & 20 Sept. & 23 Oct. & 22 Nov. \\
\hline $\mathrm{L}_{2}$ & 2 & $\circ$ & - & I.03 & - & - & I.98 & 19.0 & $6 \cdot 13$ & 7.61 & 22.0 \\
\hline $\mathrm{L}_{3}$ & 5 & 0 & - & 1.06 & - & - & 0.87 & 2.45 & 5.03 & 3.60 & 10.2 \\
\hline $\mathrm{L}_{4}$ & 8 & 0 & - & 0.87 & - & - & 0.87 & 0.95 & 3.04 & 2.00 & $4 \cdot 49$ \\
\hline L 5 & 12 & 0 & - & 0.94 & - & - & 0.89 & $I \cdot I 2$ & 1.06 & $I \cdot 8 I$ & 4.83 \\
\hline L 6 & 17 & 0 & - & 0.62 & - & - & 0.95 & 0.79 & I. 04 & I'73 & 3.04 \\
\hline$E_{I}$ & 22 & 0 & 2.63 & 0.48 & $\mathrm{I} \cdot \mathrm{I} 7$ & - & 0.69 & 0.56 & 0.69 & $I .82$ & 2.76 \\
\hline E I & 22 & 5 & 2.63 & 0.39 & I.38 & - & 0.78 & 0.47 & 0.67 & $I \cdot 75$ & 2.71 \\
\hline$E_{I}$ & 22 & 10 & $2 \cdot 38$ & 0.54 & $I \cdot 37$ & I. 5I & 0.89 & 0.47 & 0.61 & I.79 & 2.69 \\
\hline E I & 22 & 25 & $2 \cdot 63$ & 0.73 & I. 74 & - & 2.18 & $I \cdot 9 \mathrm{I}$ & 0.67 & I.77 & 2.67 \\
\hline$E_{I}$ & 22 & 50 & 2.44 & 0.62 & $2 \cdot 39$ & I. 74 & 2.23 & $2 \cdot 12$ & $\mathrm{I} \cdot 38$ & I.79 & 2.56 \\
\hline $\bar{E} I$ & 22 & 70 & $2 \cdot 67$ & 0.77 & $2 \cdot 20$ & - & $2 \cdot 38$ & 2.34 & I. 98 & $1 \cdot 71$ & $2 \cdot 8 \mathrm{I}$ \\
\hline
\end{tabular}

too, the depletion of silicate in the upper layers at E I in the summer months, as observed here in earlier years. (Atkins, I923-30; Cooper, I933). On 3 May silicate was low throughout the water column. The samples had been taken after a spell of rough bright weather, during which it is probable that vertical mixing carried silicate depletion to all depths. Phosphate was also low at all depths. The change in silicate concentration only 3 weeks later is notable.

A series of samples provided by the kindness of $\mathrm{Mr} \mathrm{R}$. A. Cox and members of the Staff of R.R.S. Discovery II from a position ( $47^{\circ} 24^{\prime} \mathrm{N}$. $7^{\circ} 52^{\prime} \mathrm{W}$.) in the North Atlantic Ocean just off the edge of the continental shelf has 
been examined, and the results are given here (Table II) because of the scarcity of observations of silicate in deep water in northern latitudes. Atkins \& Harvey (I925) report $8 \mu \mathrm{g}$. atoms $\mathrm{Si} / \mathrm{l}$. at $2000 \mathrm{~m}$. at $37^{\circ} 44^{\prime} \mathrm{N}$. $\mathrm{I} 3^{\circ} 2 \mathrm{I}^{\prime} \mathrm{W}$., and 20 at $3000 \mathrm{~m}$. at $29^{\circ} 59^{\prime} \mathrm{N}$. $15^{\circ} \mathrm{O} 3^{\prime} \mathrm{W}$.

Table II. Silicate In the North Atlantic Ocean, $47^{\circ} 24^{\prime} \mathrm{N} ., 07^{\circ} 52^{\prime} \mathrm{W}$. ON I2 MAY I950. Sounding $4030 \mathrm{M}$.

\begin{tabular}{|c|c|c|c|}
\hline $\begin{array}{l}\text { Depth } \\
\text { (m.) }\end{array}$ & $\begin{array}{c}\text { Silicate } \\
(\mu \text { g. atoms } \mathrm{Si} / 1 .)\end{array}$ & $\begin{array}{l}\text { Depth } \\
\text { (m.) }\end{array}$ & $\begin{array}{c}\text { Silicate } \\
(\mu \mathrm{g} . \text { atoms } \mathrm{Si} / 1 .)\end{array}$ \\
\hline 0 & 0.78 & 900 & 10.2 \\
\hline I0 & I.OI & I000 & $\begin{array}{l}10.8 \\
\end{array}$ \\
\hline 20 & 0.52 & II 100 & II $\cdot 7$ \\
\hline 50 & $I \cdot 76$ & 1200 & I 2.3 \\
\hline 100 & $2 \cdot 32$ & I500 & 13.3 \\
\hline I5O & $2 \cdot 6$ & 2000 & $19 \cdot \mathrm{I}$ \\
\hline 200 & 2.6 & 2500 & 28.6 \\
\hline 300 & 3.5 & 3000 & $35 \cdot 6$ \\
\hline 400 & 4.8 & 3500 & 38.7 \\
\hline 600 & $7 \cdot I$ & 3900 & 40.8 \\
\hline 800 & 10.0 & & \\
\hline
\end{tabular}

\section{SUMMARY}

A sensitive molybdenum-blue method for determining silicate based on a recent account of the chemistry of silicomolybdic acid has been applied to the analysis of sea water.

Methods of eliminating interference from phosphate and arsenate, and of reducing and evaluating the reagent blank, and some effects of temperature and timing have been studied.

A method is described which may be used with a sensitive absorptiometer for silicate concentrations in the range $0.1-50 \mu \mathrm{g}$. atoms $\mathrm{Si} / 1$.

Some results obtained with the method are presented, and illustrate change in silicate concentration of sea water on storage, and silicate in the water off Plymouth in I950, and at a position in the North Atlantic Ocean.

\section{REFERENCES}

Atkins, W. R. G., I923. The silica content of some natural waters and of culture media. Fourn. Mar. Biol. Assoc., Vol. xIII, pp. I5I-9.

- 1926. Seasonal changes in the silica content of natural waters in relation to the phytoplankton. Fourn. Mar. Biol. Assoc., Vol. xIv, pp. 89-99.

- 1928. Seasonal variations in the phosphate and silicate content of sea water during 1926 and 1927 in relation to the phytoplankton crop. Fourn. Mar. Biol. Assoc., Vol. xv, pp. I9I-205.

- 1930. Seasonal variations in the phosphate and silicate content of sea water in relation to the phytoplankton crop. Part V. November 1927 to April 1929, compared with earlier years from 1923. Fourn. Mar. Biol. Assoc., Vol. xvI, pp. 82 I-52.

Atkins, W. R. G. \& HARVEY, H. W., I925. The variation with depth of certain salts utilized in plant growth in the sea. Nature, Lond., Vol. I16, pp. 784-5. 
BoRDEIONU, C. F., I927. Colorimetric determination of phosphoric acid, particularly in phosphatic fertilizers. Ann. Sci. Univ. Fassy, Vol. 14, pp. 353-62.

Brujewicz, S. W. \& Blinov, -, I933. Estimation of silica in sea water. Bull. State Oceanogr. Inst. U.S.S.R., No. I4.

Cooper, L. H. N., I933. Chemical constituents of biological importance in the English Channel, November 1930, to January, 1932. Parts I and II. Fourn. Mar. Biol. Assoc., Vol. xvIII, pp. 677-728; pp. 729-53.

Denis, W. \& von MeYsenbug, L., I922. Note on a possible source of error in the Bell-Doisy method for the determination of phosphates in blood plasma. Fourn. Biol. Chem., Vol. 52, pp. I-3.

DiÉNERT, F. \& WANDENBULCKE, F., I923. Sur le dosage de la silice dans les eaux. C.R. Acad. Sci., Paris, T. 176, pp. 1478-80.

HARveY, H. W., I948. The estimation of phosphate and of total phosphorus in sea waters. Fourn. Mar. Biol. Assoc., Vol. xxvir, pp. 337-59.

RIEHM, H., I932. Colorimetric determination of phosphoric acid with special reference to Arrhenius' method (for soil extracts). Z. Pflanz. Dungung Bodenk., Bd. 25, No. I, pp. 323-9.

Robinson, R. J. \& SpooR, H. J., I936. Photometric determination of silicate in sea water. Ind. Eng. Chem. (Anal. Ed.), Vol. 8, pp. 455-7.

Strickland, J. D. H., I950. Silicomolybdic acid. Chemistry and Industry, p. 393, and Ph.D. Thesis, University of London, I950.

Swank, H. W. \& Mellon, M. G., I934. Colorimetric standards for silica. Ind. Eng. Chem. (Anal. Ed.), Vol. 6, pp. 348-50.

WATTENBERG, H., I937. Critical review of the methods used for determining nutrient salts and related constituents in salt water. Cons. Int. Explor. Mer, Rapp. Proc. Verb., Vol. cIII, No. 4, 33 pp. 